\title{
ANÁLISE ESTATÍSTICA DOS DADOS DE FUROS DE SONDAGEM DA JAZIDA DE COBRE DE CHAPADA, GOIÁS
}

\author{
Jorge Kazuo YAMAMOTO
}

\begin{abstract}
RESUMO
Este trabalho apresenta os resultados do tratamento estatístico e análise dos dados de litologia e teores de cobre e ouro de amostras da Jazida de Cobre de Chapada. As informações extraídas das descrições dos furos de sondagem foram confrontadas com os teores de cobre e ouro, com o fim de verificar a relação existente entre a rocha hospedeira e a mineralização. Para os teores de cobre e ouro, o tratamento estatístico foi efetuado com o objetivo de obter uma estimativa global das populações amostradas, como uma primeira aproximação do teor médio do depósito. Como a futura lavra desta jazida se daria pelo método tradicional de bancadas a céu aberto, procedeu-se à composição das amostras originais para um intervalo igual à altura das bancadas. Para aferir a qualidade da composição foi efetuado um tratamento estatístico dos teores compostos. As distribuições assim obtidas, comparadas com aquelas originais (antes da composição), revelaram uma pequena suavização e maior aproximação para a distribuição normal introduzida pela composição.
\end{abstract}

\section{ABSTRACT}

This paper presents the results of statistical analysis of lithological data and copper and gold assays from drill hole samples from the Chapada copper deposit, in Northwestern Goiás, Brasil. Rock descriptions were checked against copper and gold assays in order to verify the relation between host rock and mineralization. Frequency distributions of copper and gold assays were analyzed to obtain an overall estimate of sampled populations and also to attempt a first approximation of the average grade of the deposit. If the Chapada copper deposit were to be mined, it would be done by the traditional method of open-pit bench-cutting, hence the original samples were treated to reflect intervals equal to bench height. These composite assays were statistically analysed in order to verify the validity of compositions. The new frequency distributions dealing with the composite samples when compared with the original distributions are somewhat smoother and more closely approximate normal distributions.

\section{INTRODUÇÃO}

O tratamento estatístico e análise dos dados, feitos sob a ótica de uma análise exploratória, devem sempre que possível ser realizados com o objetivo de conhecer e caracterizar as populações dos dados em estudo, bem como controlar as transformações dos dados, como, por exemplo, por meio da composição de amostras de furos de sondagem.

Os dados utilizados neste estudo são aqueles disponíveis na Jazida de Cobre de Chapada, cuja pesquisa mineral, realizada pela Mineração Serras do Leste-MINERALESTE, resultou em mais de 10.000 amostras, as quais foram analisadas para cobre e ouro. Este trabalho foi quase que totalmente baseado na Tese de Doutoramento do autor (YAMAMOTO, 1991), que versou sobre a comparação de métodos computacionais para avaliação de reservas, sendo apresentados aqui os capítulos referentes ao tratamento estatístico prévio a que as informações foram submetidas.

\section{JAZIDA DE COBRE DE CHAPADA}

A Jazida de Cobre de Chapada resultou da pesquisa mineral realizada pela Mineração Serras do Leste-MINERALESTE, em uma área de 4.000ha, situada a sudoeste do povoado homônimo, Município e Comarca de Mara Rosa, Estado de Goiás. A área estudada está delimitada pelas coordenadas geográficas $1^{\circ} 13^{\prime} 17^{\prime \prime}$ e $14^{\circ} 15^{\prime} 05^{\prime \prime}$, de latitude sul, e 49'20'00' e 49'24'28', de longitude oeste (Figura 1).

Segundo SILVA \& SÁ (1988), a Jazida de Cobre de Chapada encontra-se inserida em um pacote de rochas metamórficas pertencentes à Seqüência Mara Rosa, de caráter vulcanosedimentar.

A estrutura predominante é um amplo e suave anticlinório de eixo NE-SW, ligeiramente complicado por ondulações de eixos NW-SE, resultante de uma evolução deformacional polifásica com três ou quatro fases de dobramentos superpostos, desenvolvendo-se famílias de juntas e de pequenas falhas (IPT, 1981a). 


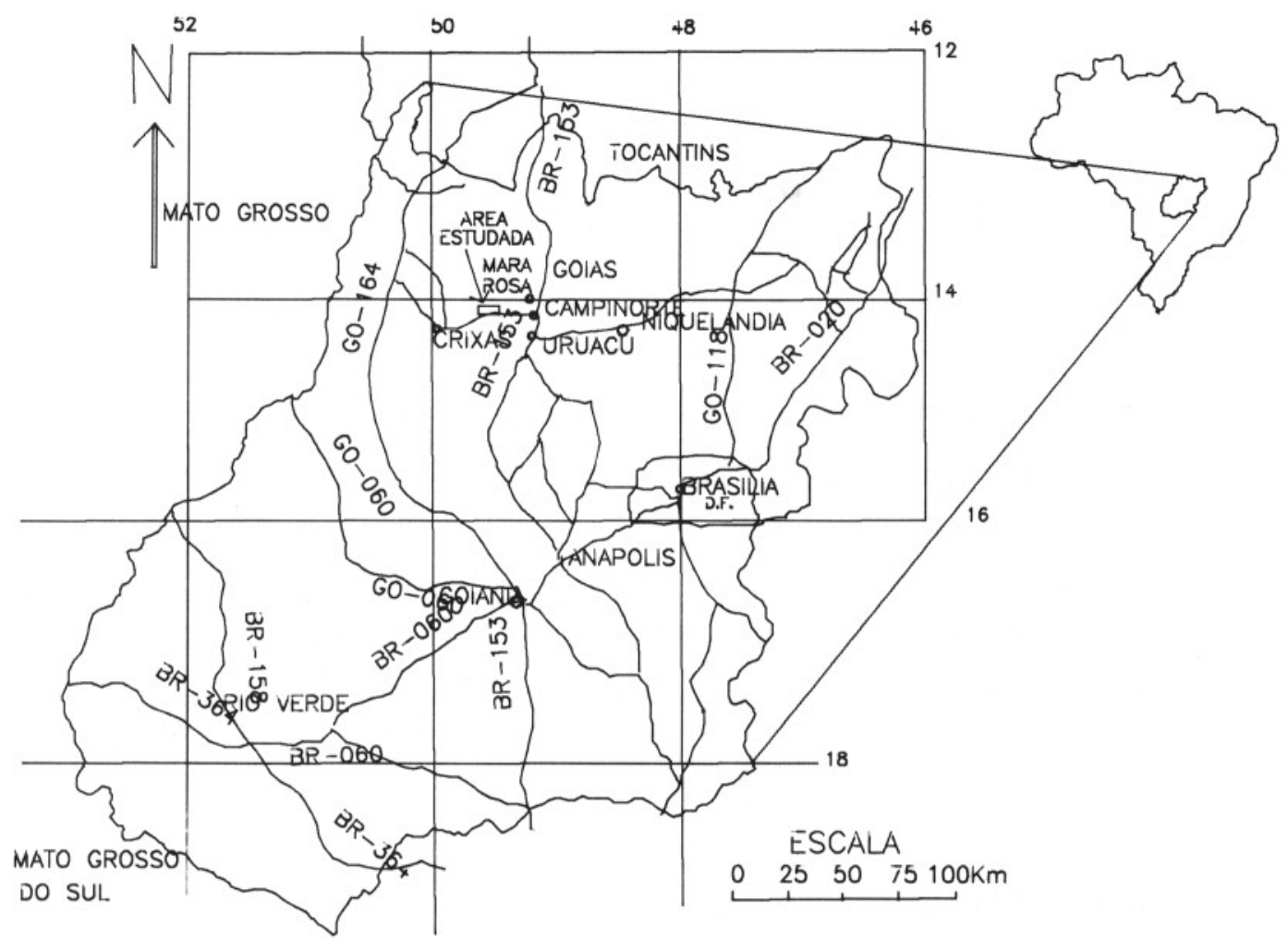

FIGURA 1 - Mapa de localização da Jazida de Cobre de Chapada, GO.

Segundo SILVA \& SÁ (1988), os principais litotipos observados em Chapada são sericitaxistos, sericita-cianita-xistos, biotita-xistos, biotita-cianita-xistos com níveis quartzíticos, xistos-quartzo feldspáticos e anfibolitos com quantidades variáveis de quartzo e feldspato.

A mineralização constitui-se fundamentalmente de calcopirita associada a pirita (sulfeto mais abundante), as quais ocorrem como finos cristais disseminados em micaxistos, principalmente biotita-xisto feldspático, com matriz silicosa de granulação fina a média (SILVA, 1979).

\section{TRATAMENTO ESTATÍSTICO E ANÁLISE DOS DADOS}

Todas as informações disponíveis dentro da área de interesse da Jazida, igual a $2,25 \mathrm{~km}^{2}$, foram consideradas no presente estudo. Tais informações são resultantes de 142 furos de sondagem, cujos testemunhos forneceram 10.829 amostras, das quais 10.502 foram analisadas para cobre e 9.029 para ouro, correspondendo respectivamente a $16.315,80 \mathrm{~m}$ e $14.070,54 \mathrm{~m}$ de testemunhos analisados.

Como foi mencionado anteriormente, este trabalho foi realizado com finalidade precípua de conhecer e caracterizar as populações de dados, bem como verificar possíveis tendências de mineralização, por meio da correla- ção de teores de cobre e ouro com os tipos litológicos.

\section{ANÁLISE DOS DADOS LITOLÓGICOS}

Com o objetivo de verificar o comportamento dos teores de cobre e ouro em relação à rocha hospedeira, bem como em relação a possíveis efeitos da presença de quartzo, cianita e feldspatização, procedeu-se a uma análise das informações litológicas, como se apresenta a seguir.

As informações litológicas ao longo dos furos de sondagem foram extraídas dos perfis de sondagem elaborados por SILVA (1979) e SILVA (1981).

Nestes perfis foram reconhecidos os seguintes grupos de litologias:

- biotita-xistos;

- sericita-xistos;

- anfibólio-xistos;

- anfibolitos;

- arenitos;

- quartzitos;

- pegmatitos.

Nestas rochas foi também anotada a presença de:

- quartzo;

- cianita;

- feldspatização. 
As informações de litologia nos furos de sondagem foram também introduzidas no arquivo de teores, prevendo a possível utilização na avaliação de reservas. No entanto, devido ao grande número de tipos litológicos reconhecidos nos perfis (pela combinação dos grupos de litologias com minerais, texturas, granulação e feldspatização) e à dificuldade de correlação das litologias, mesmo entre furos de sondagem distantes somente 50m (RICHARDSON et al., 1986), tais dados não serão utilizados como atributos para construção de variogramas ou na seleção de amostras para interpolação.

Deve-se considerar também que, com a composição de amostras para intervalos iguais à altura das bancadas, as informações de litologia se perdem. Para o caso da jazida de Chapada, que poderá ser lavrada a céu aberto, a perda da informação litológica não tem muita importância, pois toda a bancada será desmontada, controlando-se somente os teores médios dos blocos. Por outro lado, em alguns tipos de depósitos minerais em que a mineralização encontra-se controlada por um determinado tipo de rocha, a informação litológica passa a ter importância vital como atributo na seleção de amostras de furos de sondagem para avaliação do bloco e como controle para o desmonte de blocos.

Portanto, a análise que se faz das informações litológicas, tem como objetivo o melhor conhecimento da distribuição da mineralização nas rochas de Chapada.
A Tabela 1 apresenta, para a área de interesse da Jazida de Chapada, a distribuição das unidades litológicas, bem como teores médios de cobre e ouro associados às mesmas.

Os dados da Tabela 1 - que correspondem à totalidade dos testemunhos de sondagem disponíveis, ou seja, a $16.315,80 \mathrm{~m}$ analisados para cobre e $14.070,54 \mathrm{~m}$ analisados para ouro mostram que os biotita-xistos, seguidos por arenitos e sericita-xistos, são as unidades mais importantes em termos de ocorrência e teores médios associados. Embora apresentem-se razoavelmente freqüentes em Chapada, anfibólioxistos e anfibolitos $(10,1$ e $8,0 \%$, respectivamente) não são importantes como rochas mineralizadas, pois seus teores médios encontram-se abaixo dos teores médios da jazida. Os arenitos descritos nos furos de sondagem, equivalentes a $11,4 \%$ da metragem analisada, devem corresponder aos quartzitos que se apresentam com teores elevados em relação às demais litologias. Se as duas unidades fossem compostas por quartzitos, o teor médio de cobre seria $0,27 \%$ e o de ouro, 0,31 ppm. Cabe lembrar que os teores médios gerais calculados (Tabela 1) correspondem à média dos teores encontrados nas diferentes unidades litológicas, ponderados pela sua freqüência de ocorrência. Portanto, tais teores podem não corresponder necessariamente aos teores médios da jazida, pois estes só serão determinados quando da avaliação de reservas com definição do teor de corte, método de lavra, etc.

TABELA 1 - Ocorrência das unidades litológicas de Chapada e teores médios de cobre e ouro associados.

\begin{tabular}{l|c|c|c}
\hline UNIDADE LITOLÓGICA & DISTRIBUIÇÃO (\%) & COBRE $(\%)$ & OURO (ppm) \\
\hline BIOTITA-XISTOS & 45,2 & 0,30 & 0,25 \\
SERICITA-XISTOS & 11,1 & 0,27 & 0,27 \\
ANFIBÓLIO-XISTOS & 10,1 & 0,19 & 0,17 \\
ANFIBOLITOS & 8,0 & 0,12 & 0,16 \\
ARENITOS & 11,4 & 0,26 & 0,31 \\
QUARTZITOS & 0,3 & 0,54 & 0,44 \\
PEGMATITOS & 1,3 & 0,08 & 0,14 \\
SOLOS & 12,6 & N.A. & N.A. \\
\hline \multicolumn{2}{c}{ MÉDIAS GERAIS }
\end{tabular}

Continuando a análise, separaram-se das descrições as rochas que indicavam a presença de quartzo, a fim de verificar como se comportam tais rochas na presença desse mineral, em termos da mineralização associada. A Tabela 2 mostra os resultados obtidos desta análise.
Nesta tabela, observa-se que os sericita-xistos com quartzo apresentam-se com teores médios de cobre e ouro superiores às médias da unidade. Contudo, deve-se considerar também que a espessura analisada corresponde a aproximadamente $10 \%$ da espessura total da unidade. 
TABELA 2 - Ocorrência e teores médios de cobre e ouro nas unidades litológicas assinaladas com a presença de quartzo.

\begin{tabular}{l|rr|rr}
\hline & \multicolumn{2}{|c|}{ COBRE } & \multicolumn{2}{c}{ OURO } \\
UNIDADES LITOLÓGICAS & TEOR (\%) & ESPESSURA & TEOR (ppm) & ESPESSURA \\
\hline BIOTITA-XISTOS & 0,32 & $2.101,73$ & 0,25 & $1.979,05$ \\
SERICITA-XISTOS & 0,43 & 194,53 & 0,38 & 194,53 \\
ANFIBOLITOS & 0,12 & 675,43 & 0,16 & 494,46 \\
\hline MÉDIAS GERAIS & 0,28 & 0,24 \\
\hline
\end{tabular}

TABELA 3 - Ocorrência e teores médios de cobre e ouro nas unidades litológicas assinaladas com a presença de cianita.

\begin{tabular}{l|rr|rr}
\hline UNIDADES LITOLÓGICAS & \multicolumn{2}{|c|}{ COBRE } & \multicolumn{2}{c}{ OURO } \\
& TEOR $(\%)$ & ESPESSURA & TEOR $(\mathrm{ppm})$ & ESPESSURA \\
\hline BIOTITA-XISTOS & 0,25 & 881,01 & 0,23 & 758,76 \\
SERICITA-XISTOS & 0,18 & 477,85 & 0,27 & 245,23 \\
ANFIBÓLIO-XISTOS & 0,15 & 428,31 & 0,12 & 320,24 \\
\hline MÉDIAS GERAIS & 0,21 & 0,21 & \\
\hline
\end{tabular}

Com relação à presença de cianita, foram obtidos os resultados apresentados na Tabela 3 .

Pelos dados desta Tabela, nota-se que em geral os teores médios de ouro e cobre são menores que aqueles constantes nas respectivas unidades. A presença de cianita nestas rochas indica que as mesmas foram submetidas a metamorfismo de pressão e, provavelmente, este efeito po- deria ter provocado a dissolução dos sulfetos e recristalização em outras partes do depósito, ou então que estas rochas eram originalmente argilosas para geração de cianita e que por isso apresentavam teores menores de cobre e ouro. Os resultados obtidos restringem-se aos dados levantados nos perfis de sondagem, os quais foram elaborados a partir das descrições macroscópicas dos furos de sondagem.

TABELA 4 - Ocorrência e teores médios de cobre e ouro nas unidades litológicas assinaladas com a presença de feldspatização.

\begin{tabular}{l|rr|rr}
\hline UNIDADES LITOLÓGICAS & \multicolumn{2}{|c|}{ COBRE } & \multicolumn{2}{c}{ OURO } \\
& TEOR $(\%)$ & ESPESSURA & TEOR (ppm) & ESPESSURA \\
\hline BIOTITA-XISTOS & 0,30 & $4.413,07$ & 0,24 & $4.024,91$ \\
SERICITA-XISTOS & 0,25 & 250,54 & 0,19 & 224,39 \\
ANFIBÓLIO-XISTOS & 0,28 & 7,50 & 0,16 & 4,50 \\
ANFIBOLITOS & 0,52 & 11,00 & 0,55 & 11,00 \\
ARENITOS & 0,27 & 471,00 & 0,45 & 244,40 \\
\hline MÉDIAS GERAIS & 0,30 & 0,25 & \\
\hline
\end{tabular}

Quanto à feldspatização das rochas, têm-se os resultados apresentados na Tabela 4 .

Comparando-se os teores médios de cobre com os teores médios nas unidades litológicas, conforme dados da Tabela 1, não se verificam alterações nos teorès médios de cobre e ouro devido à feldspatização. Os resultados obtidos da análise das informações litológicas são concordantes com o modelo geológico proposto por KUYUMIJIAN (1990) para a Jazida de Cobre de Chapada.

\section{COMPOSIÇÃO DE AMOSTRAS DE FUROS} DE SONDAGEM

Geralmente o intervalo de amostragem nos furos de sondagem não corresponde ao intervalo de trabalho na fase de avaliação de reservas, embora tenha sido necessário analisar as amostras segundo o intervalo de amostragem, sempre menor que o intervalo de trabalho. Justifica-se isto frente à necessidade de reconhecer e delimitar possíveis zonas ricas dentro da jazida. Além disso, as amostras individuais dos 
furos de sondagem podem variar bastante em tamanho, comprimento e peso. Assim, a composição de amostras pelo agrupamento delas para o intervalo de trabalho, definido segundo a característica que se quer analisar, produzirá dados mais homogêneos e, portanto, com maior facilidade de interpretação.

É importante especificar a unidade de amostragem utilizada na avaliação de reservas, pois, segundo KIM (1990), muitos problemas surgem pela não-especificação da unidade de amostragem. Por exemplo, se uma jazida é avaliada com base na população de amostras de furos de sondagem a diamante, a produção da mina provavelmente não corresponderá às estimativas feitas, simplesmente porque a jazida não é lavrada com furos de sondagem a diamante (KIM, 1990). Segundo BARNES (1980), o objetivo de se fazer composições de amostras é de obter amostras representativas de uma unidade mineralógica particular ou unidade de mineração; os teores de amostras compostas podem ser utilizados, por meio de alguma função de extensão, para estimar o teor ou valor de um volume muito maior da mesma unidade. A composição de amostras de furos de sondagem é obtida como média ponderada do teor pelas espessuras selecionadas para o intervalo de trabalho, como mostra a equação a seguir:

$$
\mathrm{t}_{\mathrm{c}}=\stackrel{\mathrm{n}}{\sum_{\mathrm{N}}} \mathrm{t}_{\mathrm{i}} \cdot \mathrm{e}_{\mathrm{i}} /{\stackrel{\mathrm{i}}{\mathrm{L}}{ }_{1}}_{\mathrm{i}}
$$

onde: n é o número de trechos para compor o intervalo de trabalho;

$\mathrm{t}_{\mathrm{i}}$ é o teor do i-ésimo trecho;

$\mathrm{e}_{\mathrm{i}}$ é a espessura do i-ésimo trecho.

Existem muitos tipos de depósitos minerais, cada um dos quais irá requerer um tratamento especial dos dados amostrados para a obtenção dos melhores intervalos de composição para avaliação do depósito (BARNES, 1980). Basicamente, sãotrês os tipos de composiçãopossíveis em amostras de furos de sondagem para o intervalo de trabalho:

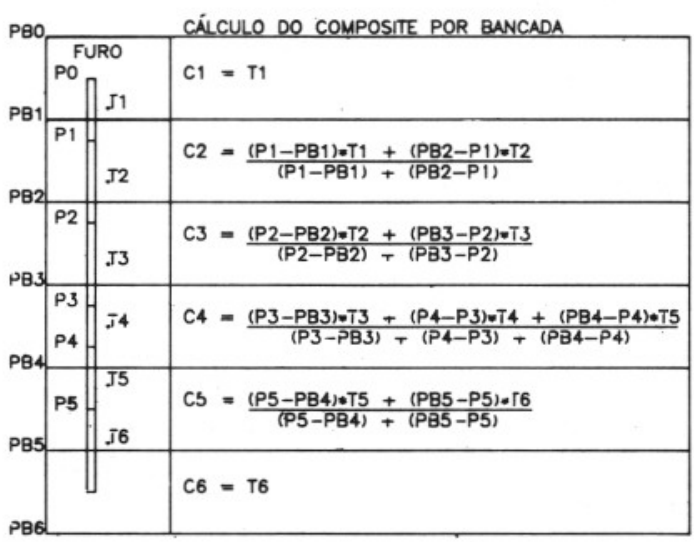

FIGURA 2-Cálculo de composição por bancadas.
- bancadas;

- tipos litológicos;

- elevações.

A composição, segundo a altura das bancadas (Figura 2), é indicada para se fazer a avaliação de reservas em depósitos, cuja lavra se dará a céu aberto. Um exemplo disso são os depósitos de cobre porfirítico, lavrados a céu aberto, que se caracterizam como depósitos disseminados de baixo teor e alta tonelagem.

O segundo tipo de composição permite obter teores representativos conforme as espessurar dos tipos litológicos reconhecidos nas seções geológicas (Figura 3). Este tipo de composição é indicado para depósitos estratiformes ou localizados em veios.

Finalmente, o último tipo permite obter composições de amostras para alguns intervalos de elevações selecionados, segundo as características geológicas, mineralógicas ou estruturais do depósito (Figura 4).

Como a futura lavra será a céu aberto pelo método tradicional de bancadas, a composição de amostras de furos de sondagem deverá ser feita para um intervalo de trabalho igual à altura das bancadas, igual a $10 \mathrm{~m}$.

Dentro da área de interesse da jazida encontram-se 142 furos de sondagem, que totalizaram 10.829 amostras, das quais 10.504 analisadas para cobre e 9.029 para ouro. As bancadas foram estabelecidas após análise da incidência dos furos de sondagem nas mesmas, calculando-se, para cad ‘ bancada de $10 \mathrm{~m}$ de altura, o número de furos de sondagem que a atravessaram, conforme resultados apresentados na Tabela 5. Assim, foram estabelecidas 17 bancadas ( 2 a 18 ) para fins de composição de amostras de furos.

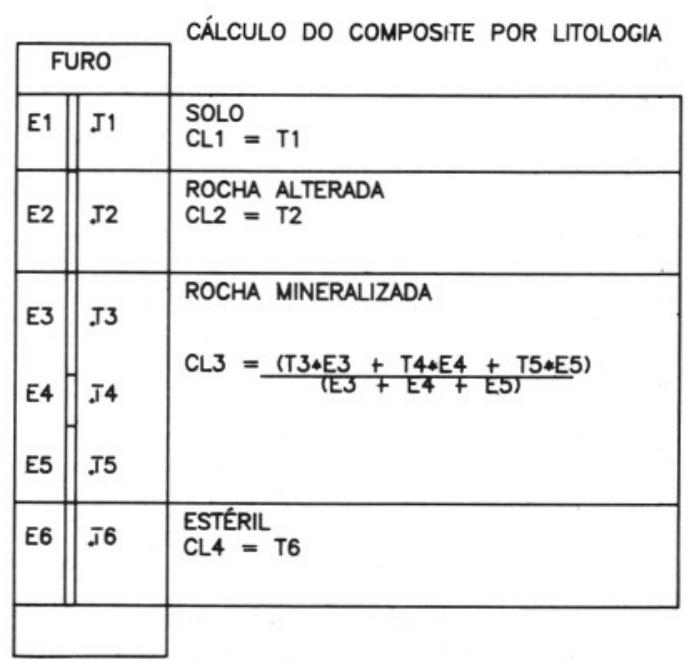

FIGURA 3 - Cálculo de composição por litologia. 


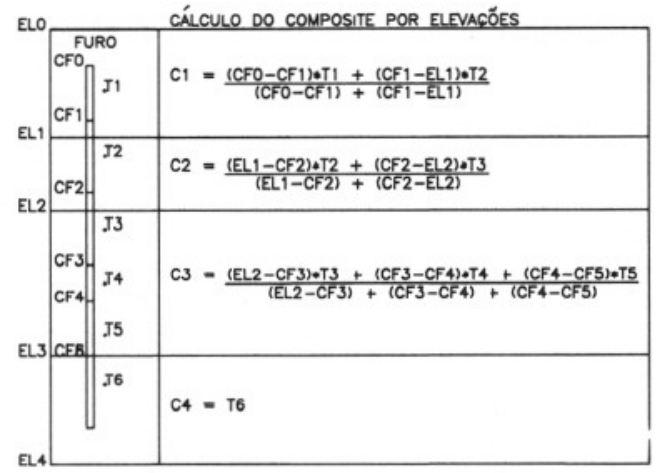

FIGURA 4 - Cálculo de composição por elevações.

\section{HISTOGRAMAS PARA DADOS ORIGINAIS DE COBRE}
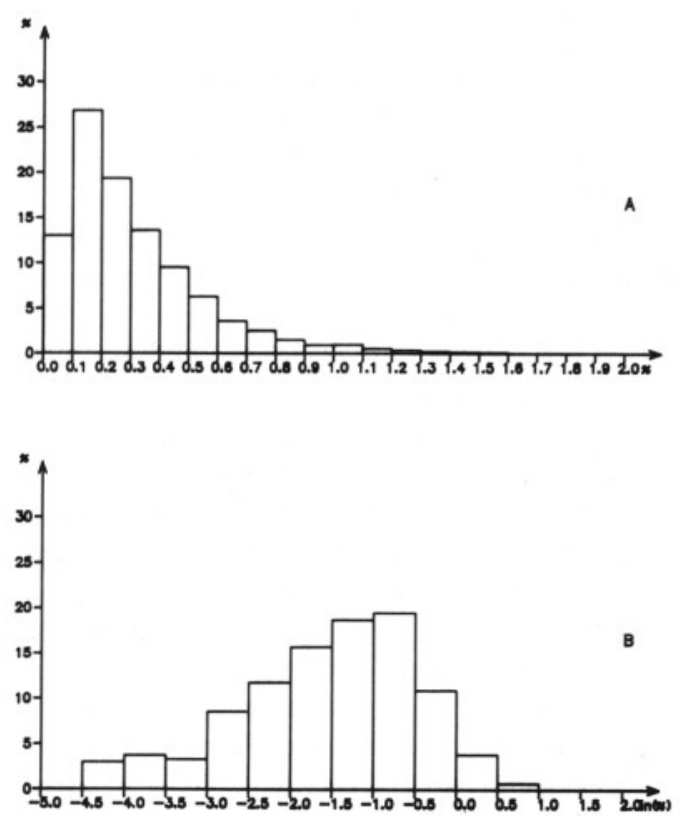

FIGURA 5 - Histogramas das distribuições de freqüências dos teores de cobre nos furos de sondagem: dos valores em \% (A) e de seus logarit$\operatorname{mos}(\mathrm{B})$.

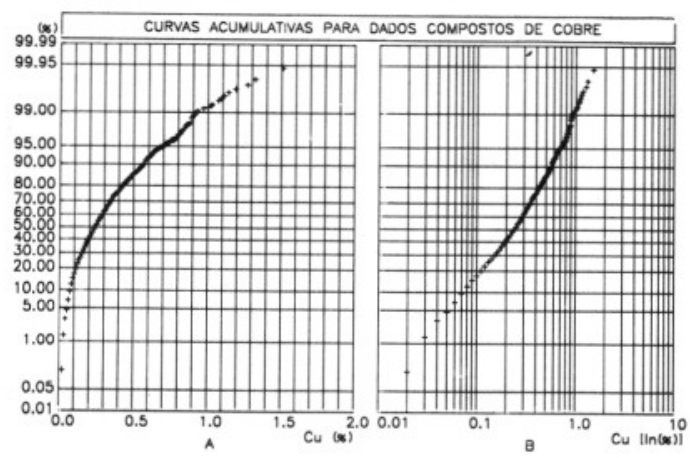

FIGURA 6-Curvas acumulativas dos teores de cobre nos furos de sondagem: em escala de probabilidade aritmética (A) e em logprobabilidade aritmética (B).
HISTOGRAMAS PARA DADOS COMPOSTOS DE COBRE
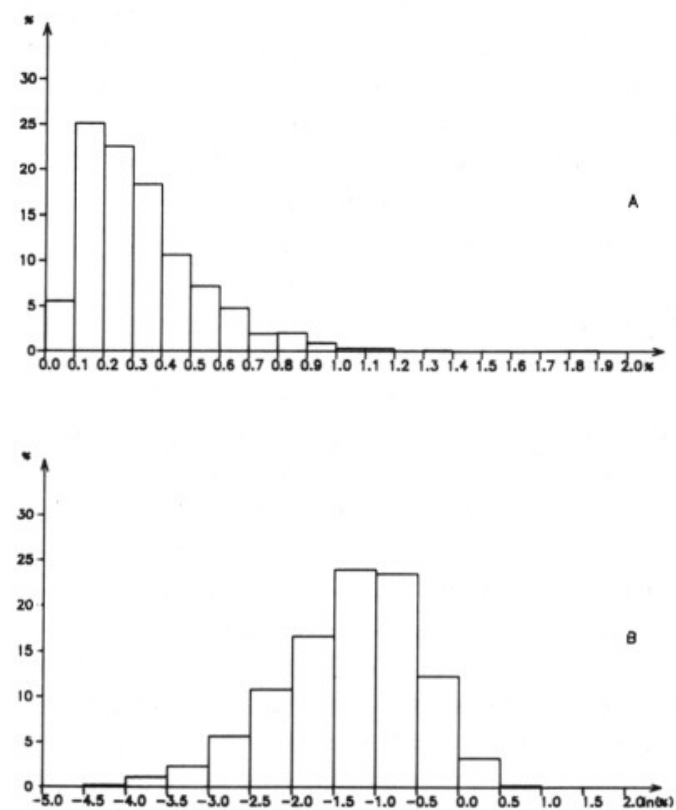

FIGURA 7 - Histogramas das distribuições de frequiências dos teores compostos de cobre dos valores em \% (A) e de seus logaritmos (B).

A composição, segundo as bancadas assim estabelecidas, foi feita por meio do programa de computação COMPN desenvolvido por KIM (1988) para microcomputadores pessoais de 16 bits e cedido por aquele autor, especificamente para esta pesquisa. O programa COMPN faz a composição furo a furo das amostras para as bancadas estabelecidas.

Os dados compostos assim obtidos constituem efetivamente o arquivo de teores para os estudos a serem realizados neste trabalho.

\section{ANÁLISE ESTATÍSTICA DOS DADOS ORIGINAIS E COMPOSTOS}

Com o objetivo de conhecer as distribuições de freqüências dos teores de ouro e cobre na Jazida de Cobre de Chapada, bem como suas características estatísticas, procedeu-se à análise estatística dos dados originais e compostos, para verificar' a suavização introduzida nos dados após a composição para altura das bancadas.

Para a análise estatística dos dados, utilizouse do programa de computação BSTAT2 (KIM, 1988), que tem como entrada o arquivo de teores originais ou compostos. Como este programa apresenta uma restrição igual a 10.000 amostras para o seu processamento e tendo em vista que o arquivo de teores originais de cobre totalizava 10.504 amostras, este arquivo foi re- 


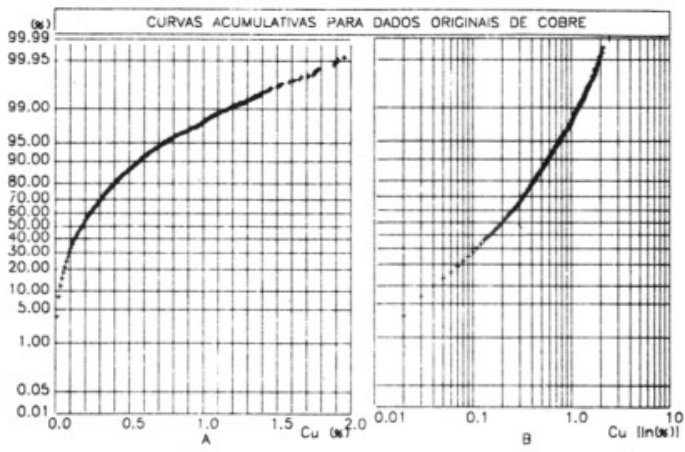

FIGURA 8 - Curvas acumulativas dos teores compostos de cobre em escala de probabilidade aritmética (A) e em log-probabilidade aritmética (B).

composto para um total de 9.998 , retirando-se aleatoriamente as amostras excedentes.

As distribuições de freqüências dos dados de cobre e ouro foram analisadas estatisticamente tanto sob a teoria normal como pela log-normal. Esta opção foi adotada, sob a ótica de uma análise exploratória dos dados, com o fim de obter

TABELA 5 - Número de furos de sondagem por bancada para a Jazida de Cobre de Chapada.

\begin{tabular}{c|c|c}
\hline BANCADA & COTAS(M) & NÚMERO DE FUROS \\
\hline 1 & $390-400$ & 27 \\
2 & $380-390$ & 78 \\
3 & $370-380$ & 96 \\
4 & $360-370$ & 110 \\
5 & $350-360$ & 128 \\
6 & $340-350$ & 136 \\
7 & $330-340$ & 142 \\
8 & $320-330$ & 142 \\
9 & $310-320$ & 142 \\
10 & $300-310$ & 141 \\
11 & $290-300$ & 139 \\
12 & $280-290$ & 133 \\
13 & $270-280$ & 123 \\
14 & $260-270$ & 113 \\
15 & $250-260$ & 101 \\
16 & $240-250$ & 87 \\
17 & $230-240$ & 73 \\
18 & $220-230$ & 46 \\
19 & $210-220$ & 30 \\
20 & $200-210$ & 19 \\
21 & $190-200$ & 8 \\
22 & $180-190$ & 8 \\
23 & $170-180$ & 7 \\
24 & $160-170$ & 5 \\
25 & $150-160$ & 3 \\
26 & $140-150$ & 1 \\
\hline
\end{tabular}

um maior número de informações estatísticas a respeito do conjunto de dados em estudo. Pode-se justificar, ainda, dizendo que a maioria das distribuições de teores de elementos úteis em jazidas segue a distribuição log-normal.

Os histogramas foram construídos tabulando-se os dados em intervalos previamente definidos. As curvas acumulativas, porém, não foram construídas juntando-se as freqüências simples lançadas no histograma, mas, sim, as freqüências valor a valor e lançando-se em gráfico de probabilidade aritmética (abscissas em teores) e log-probabilidade aritmética (abscissas em logaritmos dos teores).

Assim, todos os conjuntos de dados foram processados no programa BSTAT2 (KIM, 1988) para cálculo das estatísticas e no programa HISTO2.PAS, desenvolvido neste trabalho, para classificação dos dados, acumulação e desenho dos histogramas e curvas acumulativas.

Os parâmetros estatísticos calculados para os teores de cobre e seus logaritmos nos furos de sondagem encontram-se na Tabela 6; as distribuições de freqüências nas Tabelas 7 e 8, respectivamente para os teores e logaritmo dos teores.

As representações gráficas das distribuições de freqüências obtidas encontram-se nas Figuras 5 e 6 , histogramas e curvas acumulativas, respectivamente.

Os parâmetros estatísticos dos logaritmos dos teores foram calculados após a adição de uma constante $(\alpha=1)$.

Comparando-se os resultados da Tabela 6, verifica-se que a transformação logarítmica tornou a distribuição mais próxima da normal (pelos valores de assimetria e curtose); entretanto, em termos absolutos do coeficiente de variação, a redução foi de 0,96 para 0,80 . A estimativa obtida da média dos teores de cobre - a partir dos dados transformados, subtraída da constante adicionada e para um fator de correção geométrica igual a 1,016 - foi igual a $0,264 \%$ de cobre, ou seja, praticamente igual ao valor obtido da média aritmética dos teores, que foi igual a 0,265 (na Tabela foi arredondado para 0,27 ). Portanto, dentro da eficiência prevista por FINNEY (1941) para a média aritmética.

Nos histogramas das distribuições de freqüências dos teores de cobre e de seus logaritmos, pode-se observar a transformação introduzida na forma das mesmas. De uma distribuição fortemente assimétrica (Figura 5A) passou-se a uma distribuição levemente assimétrica (Figura 5B) ou quase simétrica.

As curvas acumulativas também refletem a mudança da forma verificada nos histogramas. A curva acumulativa das freqüências dos teores de cobre em gráfico de probabilidade aritmética 
TABELA 6 - Parâmetros estatísticos da distribuição de cobre nos furos de sondagem, segundo as teorias normal e log-normal.

\begin{tabular}{lrr}
\hline PARÂMETROS ESTATÍSTICOS & NORMAL & LOG-NORMAL \\
\hline MÉDIA & $0,27 \%$ & 0,22 \\
VARIÂNCIA & $0,065 \% \%^{2}$ & 0,03 \\
DESVIO PADRÃO & $0,25 \%$ & 0,18 \\
ASSIMETRIA & 2,38 & 0,24 \\
CURTOSE & 13,33 & $-0,57$ \\
COEFICIENTE DE VARIAÇÃO & 0,96 & 0,80 \\
NÚMERO DE AMOSTRAS & 9998 & 9998 \\
\hline
\end{tabular}

TABELA 7 - Distribuição de frequêencias dos teores de cobre nos furos de sondagem.

\begin{tabular}{cccc}
\hline $\begin{array}{c}\text { CLASSES } \\
(\%)\end{array}$ & OBSERVADA & $\begin{array}{c}\text { F R E Q Ü Ê N C I A S } \\
\text { RELATIVA }\end{array}$ & ACUMULADA \\
\hline 0,00 A 0,10 & 1304 & 13,04 & 13,04 \\
0,10 A 0,20 & 2683 & 26,84 & 39,88 \\
0,20 A 0,30 & 1933 & 19,33 & 59,21 \\
0,30 A 0,40 & 1365 & 13,65 & 72,86 \\
0,40 A 0,50 & 955 & 9,55 & 82,42 \\
0,50 A 0,60 & 633 & 6,33 & 88,75 \\
0,60 A 0,70 & 360 & 3,60 & 92,35 \\
0,70 A 0,80 & 256 & 2,56 & 94,91 \\
0,80 A 0,90 & 153 & 1,53 & 96,44 \\
0,90 A 1,00 & 93 & 0,93 & 97,37 \\
1,00 A 1,10 & 96 & 0,96 & 98,33 \\
1,10 A 1,20 & 51 & 0,51 & 98,84 \\
1,20 A 1,30 & 37 & 0,37 & 99,21 \\
1,30 A 1,40 & 25 & 0,25 & 99,46 \\
1,40 A 1,50 & 16 & 0,16 & 99,76 \\
1,50 A 1,60 & 14 & 0,14 & 99,81 \\
1,60 A 1,70 & 5 & 0,05 & 99,86 \\
1,70 A 1,80 & 5 & 0,05 & 99,91 \\
1,80 A 1,90 & 5 & 0,05 & 99,95 \\
1,90 A 2,00 & 4 & 0,04 & 99,96 \\
2,00 A 2,10 & 1 & 0,01 & 99,98 \\
2,10 A 2,20 & 2 & 0,02 & 99,99 \\
2,40 A 2,50 & 1 & 0,01 & 100,00 \\
4,50 A 4,60 & 1 & 0,01 & \\
\hline TOTAIS & 9998 & 100,00 & \\
\hline
\end{tabular}

(Figura 6A) quando plotada em termos de seus logaritmos na mesma escala (Figura 6B) aproxima-se de uma reta, que seria a representação de uma distribuição normal.

Mantendo-se as mesmas condições e repetindo-se todo o procedimento para os teores de cobre compostos para a altura das bancadas, obtiveram-se os parâmetros estatísticos da Tabela 9; as distribuições de freqüências para os teores compostos e seus logaritmos das Tabelas 10 e 11, respectivamente; os histogramas da Figura 7 e as curvas acumulativas da Figura 8 .

Comparando-se os resultados da Tabela 9 com os da Tabela 6, verifica-se que a composição das amostras dos furos de sondagem para a altura das bancadas introduziu uma suavização nos dados, como seria de esperar, refletida na diminuição da variância e do coeficiente de variação para uma média praticamente igual.

Agora, observando-se os parâmetros estatísticos da Tabela 9, nota-se também uma redução nas medidas de dispersão, bem como na forma da distribuição que se aproxima muito da normal, indicada pela sensível diminuição da assimetria. Aplicando o fator de correção geométrica igual a 1,011 sobre a média geométrica, obteve-se uma estimativa do teor médio log-normal de cobre exatamente igual à média aritmética.

Os histogramas da Figura 7 para os teores de cobre compostos para as bancadas mostram que, em relação aos da Figura 5, a composição de amostras produziu uma distribuição mais próxima da normal, dada pela simetria do histograma da Figura 7. Com relação às curvas acumulativas, constata-se o mesmo efeito exposto anteriormente em que a distribuição acumulada em gráfico de log-probabilidade aproxima-se da reta (Figura $8 \mathrm{~B}$ ).

Comparando-se todos os resultados obtidos entre os dados originais e compostos, nota-se que a composição dos teores de cobre nos furos de sondagem para a altura das bancadas não intro- 
TABELA 8 - Distribuição de freqüências dos logaritmos dos teores de cobre nos furos de sondagem.

\begin{tabular}{cccc}
\hline $\begin{array}{c}\text { CLASSES } \\
\text { ln }(\%)\end{array}$ & OBSERVADA & $\begin{array}{c}\text { F R Q U Ü E N C I A S } \\
\text { RELATIVA }\end{array}$ & ACUMULADA \\
\hline$-4,5$ A -4,0 & 299 & 2,99 & 2,99 \\
$-4,0$ A -3,5 & 381 & 3,81 & 6,80 \\
$-3,5$ A -3,0 & 333 & 3,33 & 10,13 \\
$-3,0$ A -2,5 & 859 & 8,59 & 18,72 \\
$-2,5$ A -2,0 & 1178 & 11,78 & 30,51 \\
$-2,0$ A -1,5 & 1573 & 15,73 & 46,24 \\
$-1,5$ A -1,0 & 1870 & 18,70 & 64,94 \\
$-1,0$ A -0,5 & 1949 & 19,49 & 84,44 \\
$-0,5$ A 0,0 & 1094 & 10,94 & 95,38 \\
0,0 A 0,5 & 390 & 3,90 & 99,28 \\
0,5 A 1,0 & 70 & 0,70 & 99,98 \\
1,0 A 1,5 & 1 & 0,01 & 99,99 \\
1,5 A 2,0 & 1 & 0,01 & 100,00 \\
\hline TOTAIS & 9998 & 100,00 & \\
\hline
\end{tabular}

TABELA 9 - Parâmetros estatísticos da distribuição de cobre nas bancadas, segundo as teorias normal e log-normal.

\begin{tabular}{lrr}
\hline PARÂMETROS ESTATÍSTICOS & NORMAL & LOG-NORMAL \\
\hline MÉDIA & $0,28 \%$ & 0,24 \\
VARIÂNCIA & $0,043 \% \%^{2}$ & 0,02 \\
DESVIO PADRÃO & $0,21 \%$ & 0,15 \\
ASSIMETRIA & 1,52 & 0,13 \\
CURTOSE & 3,67 & $-0,52$ \\
COEFICIENTE DE VARIAÇÃO & 0,74 & 0,64 \\
NÚMERO DE AMOSTRAS & 1596 & 1596 \\
\hline
\end{tabular}

duziu grandes modificações nas distribuições de freqüências dos dados, bem como em termos de seus valores absolutos, mostrando que esses dados são confiáveis para fins de avaliação de reservas. Cabe ressaltar que se a suavização fosse grande, introduzida pela composição de amostras usando uma altura inadequada, as reservas seriam subestimadas com a diluição, dos teores mais altos em relação aos mais baixos, provada pela composição.
Repetindo o processamento para os teores de ouro nas amostras dos furos de sondagem, obtiveram-se os parâmetros estatísticos listados na Tabela 12, as distribuições de freqüências dos teores de ouro e logaritmos dos teores nas Tabelas 13 e 14, respectivamente, e suas representações gráficas nos histogramas da Figura 9 e curvas acumulativas da Figura 10.

A exemplo dos teores de cobre, os parâmetros estatísticos - calculados para os teores de

TABELA 10 - Distribuição de frequêencias dos teores de cobre compostos para as bancadas.

\begin{tabular}{cccr}
\hline $\begin{array}{c}\text { CLASSES } \\
(\%)\end{array}$ & OBSERVADA & $\begin{array}{c}\text { F R E Q Ü Ê N C I A S } \\
\text { RELATIVA }\end{array}$ & ACUMULADA \\
\hline 0,00 A 0,10 & 88 & 5,51 & 5,51 \\
0,10 A 0,20 & 401 & 25,13 & 30,64 \\
0,20 A 0,30 & 360 & 22,56 & 53,20 \\
0,30 A 0,40 & 294 & 18,42 & 71,62 \\
0,40 A 0,50 & 169 & 10,59 & 82,21 \\
0,50 A 0,60 & 115 & 7,21 & 89,41 \\
0,60 A 0,70 & 77 & 4,82 & 94,24 \\
0,70 A 0,80 & 31 & 1,94 & 96,18 \\
0,80 A 0,90 & 32 & 2,01 & 98,18 \\
0,90 A 1,00 & 14 & 0,88 & 99,06 \\
1,00 A 1,10 & 5 & 0,31 & 99,37 \\
1,10 A 1,20 & 5 & 0,31 & 99,69 \\
1,20 A 1,30 & 1 & 0,06 & 99,75 \\
1,30 A 1,40 & 2 & 0,13 & 99,87 \\
1,40 A 1,50 & 0 & 0,00 & 99,87 \\
1,50 A 1,60 & 1 & 0,06 & 99,94 \\
1,60 A 1,70 & 0 & 0,00 & 100,00 \\
1,70 A 1,80 & 1 & 0,06 & \\
\hline TOTAIS & 1596 & 100,00 & \\
\hline
\end{tabular}




\section{HISTOGRAMAS PARA DADOS ORIGINAIS DE OURO}
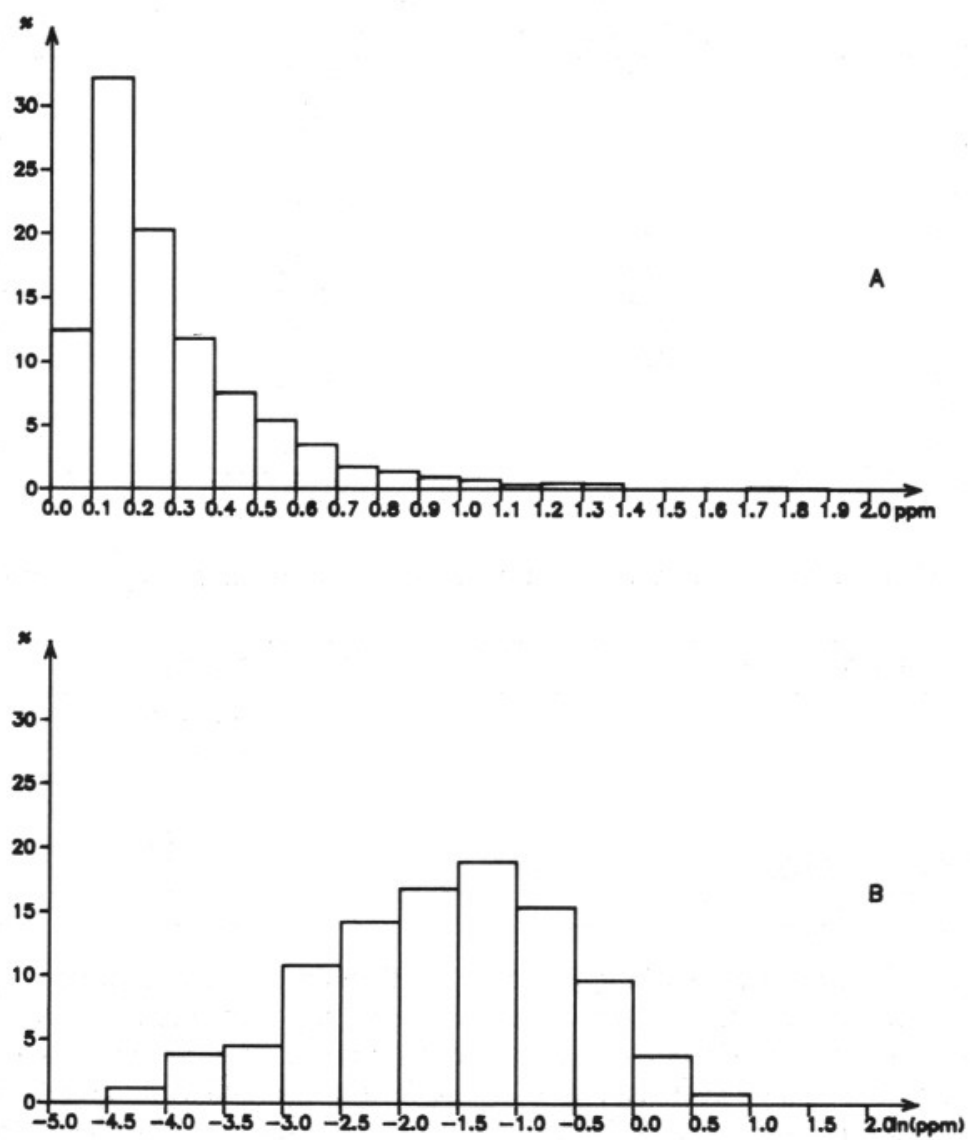

FIGURA 9 - Histogramas das distribuições de freqüências dos teores de ouro nos furos de sondagem: dos valores em ppm (A) e de seus logaritmos (B).

TABELA 11 - Distribuição de freqüências dos logaritmos dos teores de cobre compostos para as bancadas.

\begin{tabular}{cccr}
\hline $\begin{array}{c}\text { CLASSES } \\
\ln (\%)\end{array}$ & OBSERVADA & $\begin{array}{c}\text { F R Q Ü Ê N C I A S } \\
\text { RELATIVA }\end{array}$ & ACUMULADA \\
\hline & 3 & 0,19 & 0,19 \\
$-4,5$ A $-4,0$ & 18 & 1,13 & 1,32 \\
$-4,0$ A $-3,5$ & 37 & 2,32 & 3,63 \\
$-3,5$ A $-3,0$ & 90 & 5,64 & 9,27 \\
$-3,0$ A $-2,5$ & 172 & 10,78 & 20,05 \\
$-2,5$ A - 2,0 & 266 & 16,67 & 36,72 \\
$-2,0$ A $-1,5$ & 383 & 24,00 & 60,71 \\
$-1,5$ A $-1,0$ & 376 & 23,56 & 84,27 \\
$-1,0$ A -0,5 & 196 & 12,28 & 96,55 \\
$-0,5$ A 0,0 & 52 & 3,26 & 99,81 \\
0,0 A 0,5 & 3 & 0,19 & 100,00 \\
0,5 A 1,0 & 1596 & 100,00 & \\
\hline
\end{tabular}




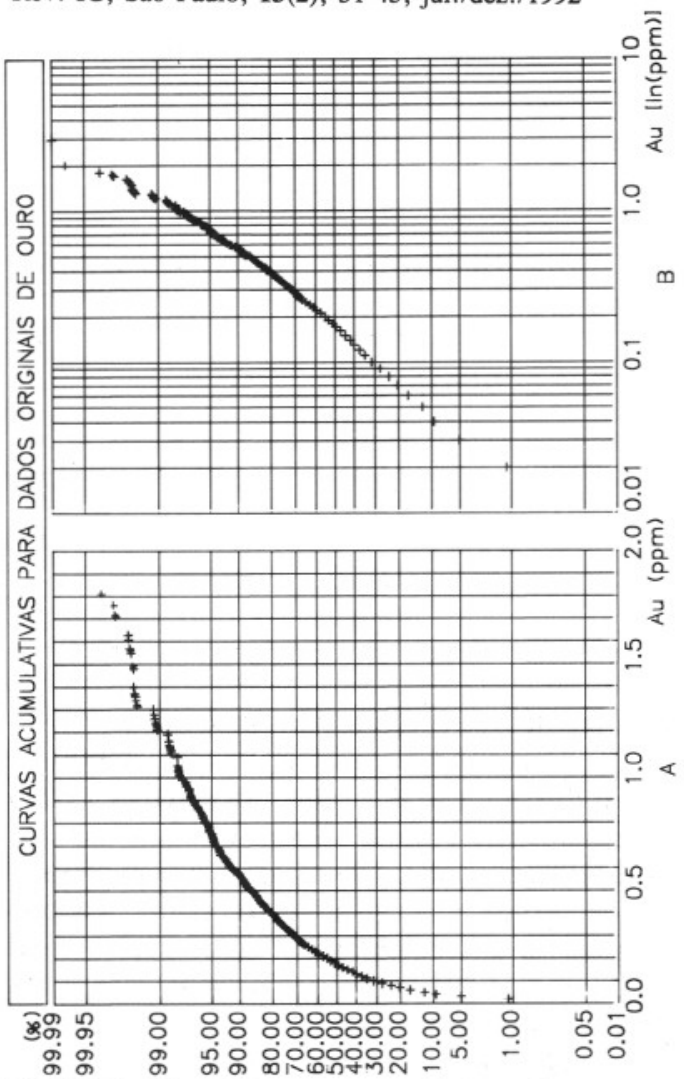

FIGURA 10 - Curvas acumulativas dos teores de ouro nos furos de sondagem: em escala de probabilidade aritmética (A) e em logprobabilidade aritmética (B).

HISTOGRAMAS PARA DADOS COMPOSTOS DE OURO
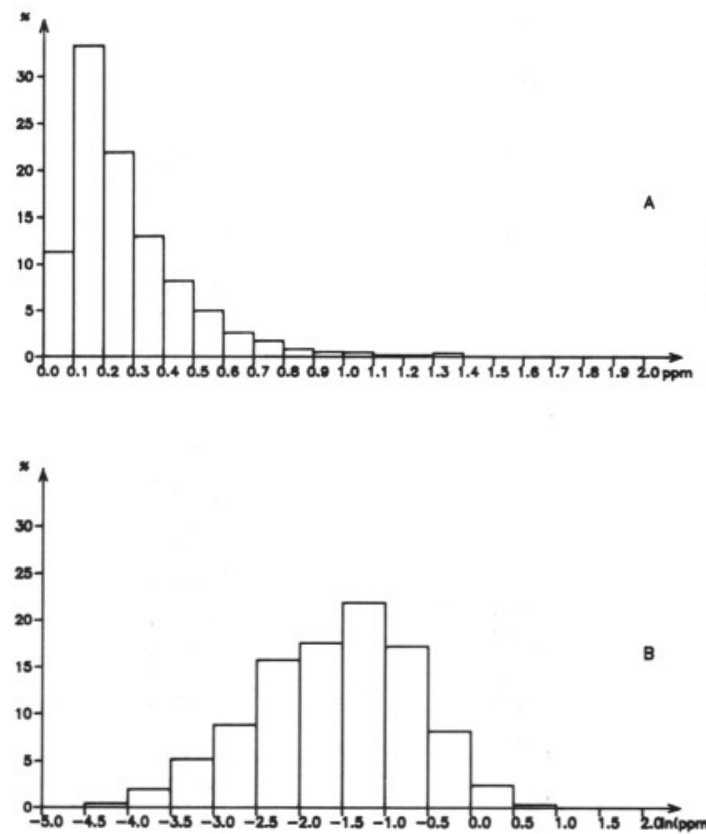

FIGURA 11 - Histogramas das distribuições de freqüências dos teores compostos de ouro: dos valores em ppm (A) e de seus logaritmos (B).

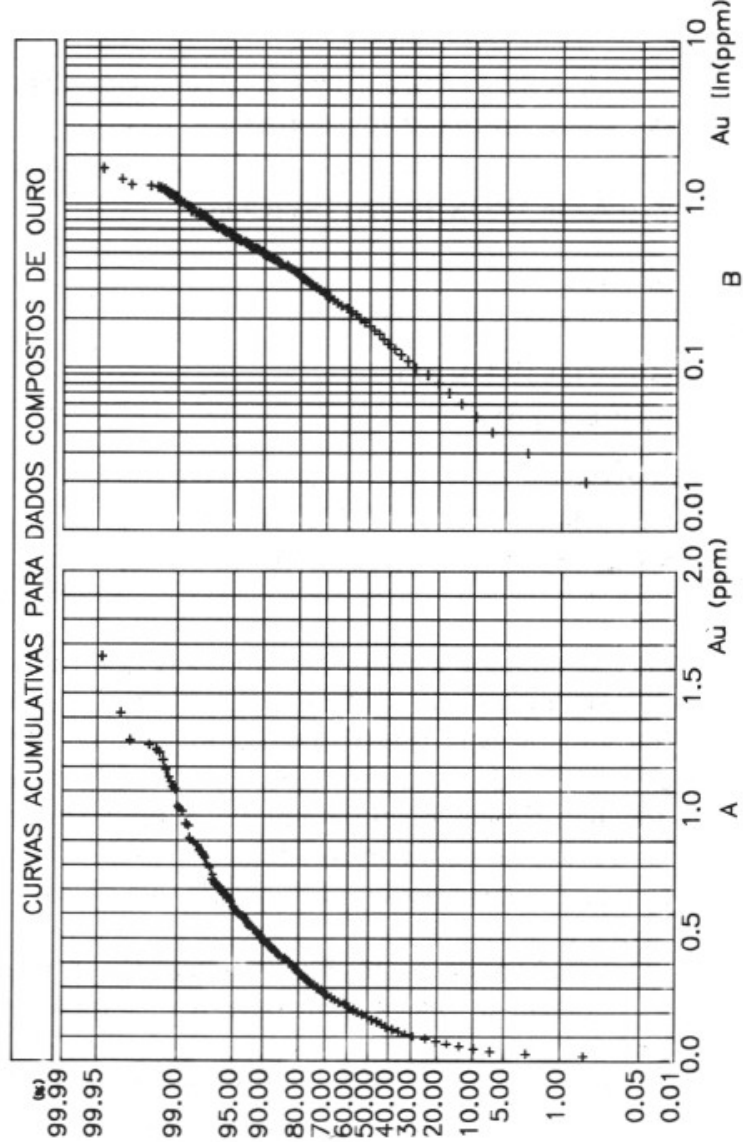

FIGURA 12 - Curvas acumulativas dos teores compostos de ouro em escala de probabilidade aritmética (A) e em log-probabilidade aritmética (B).

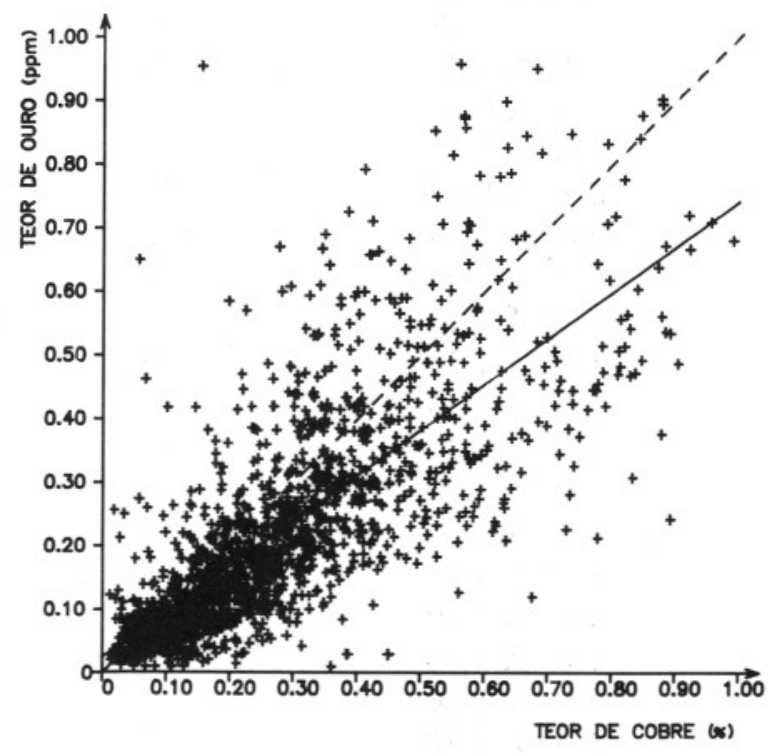

FIGURA 13 - Diagrama de dispersão entre os teores compostos de ouro e cobre. A linha cheia representa a reta de regressão dos mínimos quadrados e a tracejada, a reta ideal 1:1. 
TABELA 12 - Parâmetros estatísticos da distribuição de ouro nos furos de sondagem, segundo as teorias normal e log-normal.

\begin{tabular}{lrr}
\hline PARÂMETROS ESTATÍSTICOS & NORMAL & LOG-NORMAL \\
\hline MÉDIA & $0,25 \mathrm{ppm}$ & 0,20 \\
VARIÂNCIA & $0,065 \mathrm{ppm}^{2}$ & 0,03 \\
DESVIO PADRÃO & $0,25 \mathrm{ppm}$ & 0,17 \\
ASSIMETRIA & 2,70 & 0,08 \\
CURTOSE & 15,09 & $-0,61$ \\
COEFICIENTE DE VARIAÇÃO & 1,03 & 0,85 \\
NÚMERO DE AMOSTRAS & 9029 & 9029 \\
\hline
\end{tabular}

ouro e seus logaritmos das amostras dos furos de sondagem - confirmam a normalização introduzida pela transformação logarítmica. $\mathrm{O}$ teor médio de ouro estimado a partir da média dos logaritmos resultou em $0,25 \mathrm{ppm}$ (fator de correção geométrica igual a 1,016), que é exatamente o valor obtido pela média aritmética.

Observando-se os histogramas da Figura 9 , constata-se que a distribuição dos logarit- mos dos teores (Figura 9B) aproxima-se muito de uma distribuição normal, o que comprova que a distribuição dos teores originais de ouro é log-normal. Apesar disso, verificou-se que as estatísticas obtidas são significativas, principalmente em relação à média aritmética que caracteriza eficientemente a distribuição original, pois os coeficientes de variação calculados apresentaram-se sempre inferiores a 1,2, como observado por FINNEY (1941).

TABELA 13 - Distribuição de freqüências dos teores de ouro nos furos de sondagem.

\begin{tabular}{crcr}
\hline $\begin{array}{c}\text { CLASSES } \\
(\mathrm{ppm})\end{array}$ & OBSERVADA & $\begin{array}{c}\text { F R E Q Ü Ê N C I A S } \\
\text { RELATIVA }\end{array}$ & ACUMULADA \\
\hline 0,00 A 0,10 & 1122 & 12,43 & 12,43 \\
0,10 A 0,20 & 2899 & 32,11 & 44,53 \\
0,20 A 0,30 & 1830 & 20,27 & 64,80 \\
0,30 A 0,40 & 1067 & 11,82 & 76,62 \\
0,40 A 0,50 & 686 & 7,60 & 84,22 \\
0,50 A 0,60 & 493 & 5,46 & 89,68 \\
0,60 A 0,70 & 319 & 3,53 & 93,21 \\
0,70 A 0,80 & 162 & 1,79 & 95,00 \\
0,80 A 0,90 & 128 & 1,42 & 96,42 \\
0,90 A 1,00 & 89 & 0,99 & 97,41 \\
1,00 A 1,10 & 69 & 0,76 & 98,17 \\
1,10 A 1,20 & 38 & 0,42 & 98,59 \\
1,20 A 1,30 & 48 & 0,53 & 99,13 \\
1,30 A 1,40 & 42 & 0,47 & 99,59 \\
1,40 A 1,50 & 2 & 0,02 & 99,61 \\
1,50 A 1,60 & 3 & 0,03 & 99,65 \\
1,60 A 1,70 & 4 & 0,04 & 99,69 \\
1,70 A 1,80 & 12 & 0,13 & 99,82 \\
1,80 A 1,90 & 7 & 0,08 & 99,90 \\
1,90 A 2,00 & 0 & 0,00 & 99,90 \\
2,00 A 2,10 & 7 & 0,08 & 99,98 \\
2,90 A 3,00 & 1 & 0,01 & 99,99 \\
4,30 A 4,40 & 1 & 0,01 & 100,00 \\
\hline TOTAIS & 9029 & 100,00 & \\
\hline
\end{tabular}


Nas curvas acumulativas da Figura 10, confirmam-se as mesmas observações feitas sobre os respectivos histogramas.

Com o objetivo de estudar a distribuição dos teores de ouro compostos para as bancadas repetiu-se o procedimento descrito, mantendo- se as mesmas condições de processamento, obtendo-se os parâmetros estatísticos da Tabela 15 , as distribuições de freqüências dos teores compostos e seus logaritmos das Tabelas 16 e 17 e, finalmente, os histogramas da Figura 11 e as curvas acumulativas da Figura 12.

TABELA 14 - Distribuição de frequêencias dos logaritmos dos teores de ouro nos furos de sondagem.

\begin{tabular}{cccr}
\hline $\begin{array}{c}\text { CLASSES } \\
\ln (\mathrm{ppm})\end{array}$ & OBSERVADA & $\begin{array}{c}\text { F R Q Ü Ê N C I A S } \\
\text { RELATIVA }\end{array}$ & ACUMULADA \\
\hline$-4,5$ A $-4,0$ & 106 & 1,17 & 1,17 \\
$-4,0$ A -3,5 & 347 & 3,84 & 5,02 \\
$-3,5$ A -3,0 & 408 & 4,52 & 9,54 \\
$-3,0$ A -2,5 & 974 & 10,79 & 20,32 \\
$-2,5$ A -, 0 & 1285 & 14,23 & 34,56 \\
$-2,0$ A -1,5 & 1520 & 16,83 & 51,39 \\
$-1,5$ A - 1,0 & 1709 & 18,93 & 70,32 \\
$-1,0$ A -0,5 & 1391 & 15,41 & 85,72 \\
$-0,5$ A 0,0 & 873 & 9,67 & 95,39 \\
0,0 A 0,5 & 342 & 3,79 & 99,18 \\
0,5 A 1,0 & 72 & 0,80 & 99,98 \\
1,0 A 1,5 & 1 & 0,01 & 99,99 \\
1,5 A 2,0 & 1 & 0,01 & 100,00 \\
\hline TOTAIS & 9029 & 100,00 & \\
\hline
\end{tabular}

Os resultados obtidos para os teores de ouro compostos para as bancadas confirmam a leve suavização introduzida nos dados pela composição que, seguramente, não irá comprometer os resultados de avaliações de reservas que se processarem. A estimativa da média dos teores feita por meio da média dos logaritmos, corrigida por um fator de correção geométrica igual a 1,011, resultou novamente num valor exatamente igual à média aritmética.

Os histogramas da Figura 11 mostram, a exemplo dos dados anteriores, a mesma feição geral, que confirma mais uma vez o caráter lognormal da distribuição dos teores de ouro também nas bancadas. As curvas acumulativas da Figura 8 também confirmam as observações feitas anteriormente, onde os pontos no gráfico de log-probabilidade aritmética alinham-se praticamente sobre uma reta.

Comparando-se os resultados da análise estatística feita para o ouro nos furos de sondagem e nas bancadas, conclui-se que a composição produziu uma leve suavização nos dados em termos de distribuição dos teores.

TABELA 15 - Parâmetros estatísticos da distribuição de ouro nas bancadas, segundo as teorias normal e log-normal.

\begin{tabular}{lcc}
\hline PARÂMETROS ESTATÍSTICOS & NORMAL & LOG-NORMAL \\
\hline MÉDIA & $0,23 \mathrm{ppm}$ & 0,20 \\
VARIÂNCIA & $0,045 \mathrm{ppm}^{2}$ & 0,02 \\
DESVIO PADRÃO & $0,21 \mathrm{ppm}$ & 0,15 \\
ASSIMETRIA & 2,23 & 0,21 \\
CURTOSE & 7,65 & 0,51 \\
COEFICIENTE DE VARIAÇÃO & 0,91 & 0,77 \\
NÚMERO DE AMOSTRAS & 1596 & 1596 \\
\hline
\end{tabular}


TABELA 16 - Distribuição de freqüências dos teores de ouro compostos para as bancadas.

\begin{tabular}{cccc}
\hline $\begin{array}{c}\text { CLASSES } \\
(\mathrm{ppm})\end{array}$ & OBSERVADA & $\begin{array}{c}\text { F R E Q U Ê N C I A S } \\
\text { RELATIVA }\end{array}$ & ACUMULADA \\
\hline 0,00 A 0,10 & 180 & 11,28 & 11,28 \\
0,10 A 0,20 & 531 & 33,27 & 44,55 \\
0,20 A 0,30 & 350 & 21,93 & 66,48 \\
0,30 A 0,40 & 207 & 12,97 & 79,45 \\
0,40 A 0,50 & 131 & 8,21 & 87,66 \\
0,50 A 0,60 & 80 & 5,01 & 92,67 \\
0,60 A 0,70 & 42 & 2,63 & 95,30 \\
0,70 A 0,80 & 28 & 1,75 & 97,06 \\
0,80 A 0,90 & 14 & 0,88 & 97,93 \\
0,90 A 1,00 & 9 & 0,56 & 98,50 \\
1,00 A 1,10 & 8 & 0,50 & 99,00 \\
1,10 A 1,20 & 3 & 0,19 & 99,19 \\
1,20 A 1,30 & 3 & 0,19 & 99,37 \\
1,30 A 1,40 & 7 & 0,44 & 99,81 \\
1,40 A 1,50 & 1 & 0,06 & 99,87 \\
1,50 A 1,60 & 0 & 0,00 & 99,87 \\
1,60 A 1,70 & 1 & 0,06 & 99,94 \\
1,70 A 1,80 & 0 & 0,00 & 99,94 \\
1,80 A 1,90 & 0 & 0,00 & 99,94 \\
1,90 A 2,00 & 1 & 0,06 & 100,00 \\
\hline TOTAIS & 1596 & 100,00 & \\
\hline
\end{tabular}

\section{CORRELAÇÃO DOS TEORES} COMPOSTOS DE COBRE E OURO

Com os teores de cobre e ouro compostos para a altura das bancadas procedeu-se a um estudo de correlação dos mesmos, lançando-se estas informações em diagrama de dispersão, onde se mediu também o coeficiente de correlação linear. O diagrama de dispersão dos teores de ouro em função dos de cobre encontra-se no desenho da Figura 13 e os coeficientes da reta dos mínimos quadrados e de correlação linear, na Tabela 18 .

TABELA 17 - Distribuição de freqüências dos logaritmos dos teores de ouro compostos para as bancadas.

\begin{tabular}{cccc}
\hline $\begin{array}{c}\text { CLASSES } \\
\ln (\mathrm{ppm})\end{array}$ & OBSERVADA & $\begin{array}{c}\text { F R E Q U E N C I A S } \\
\text { RELATIVA }\end{array}$ & ACUMULADA \\
\hline$-4,5$ A -4,0 & 7 & 0,44 & 0,44 \\
$-4,0$ A -3,5 & 32 & 2,01 & 2,44 \\
$-3,5$ A -3,0 & 83 & 5,20 & 7,64 \\
$-3,0$ A -2,5 & 142 & 8,90 & 16,54 \\
$-2,5$ A -2,0 & 252 & 15,79 & 32,33 \\
$-2,0$ A -1,5 & 281 & 17,61 & 49,94 \\
$-1,5$ A -1,0 & 349 & 21,87 & 71,80 \\
$-1,0$ A -0,5 & 275 & 17,23 & 89,04 \\
$-0,5$ A 0,0 & 130 & 8,15 & 97,18 \\
0,0 A 0,5 & 39 & 2,44 & 99,62 \\
0,5 A 1,0 & 6 & 0,38 & 100,00 \\
\hline TOTAIS & 1596 & 100,00 & \\
\hline
\end{tabular}

TABELA 18 - Coeficientes da reta dos mínimos quadrados ( $\mathrm{a}$ e b da equação: $\mathrm{Y}=\mathrm{a}+\mathrm{bX}$ ) e de correlação linear calculados (cc) para os teores de ouro em função de cobre.

\begin{tabular}{cccc}
\hline $\mathrm{a}$ & $\mathrm{b}$ & $\mathrm{cc}$ & nd \\
\hline 0,024 & 0,717 & 0,769 & 1567 \\
\hline
\end{tabular}

Neste diagrama pode-se observar que existe uma boa correlação entre os teores de ouro e cobre, confirmando a grande semelhança entre os histogramas e curvas acumulativas desses elementos. Pela reta dos mínimos quadrados e, também, pela nuvem de pontos, pode-se afirmar que em média os teores de cobre são superiores aos de ouro. 


\section{CONSIDERAÇÕES FINAIS}

Este tipo de análise estatística deve ser feito previamente em qualquer trabalho de avaliação de reservas, para evitar resultados desastrosos de reservas; por exemplo, pela utilização de uma altura inadequada para composição de amostras, ou ainda por possíveis erros nos dados que poderiam ser facilmente detectados tanto nas tabelas de distribuição de freqüências como nas suas representações gráficas, por meio de histogramas e curvas acumulativas. Tais erros são geralmente atribuídos a problemas analíticos e, ultimamente com o uso de computadores, a erros de digitação. Além disso, obviamente o controle que se tem das distribuições estatísticas dos dados originais e compostos, será de grande valia, quando se obtiverem os teores médios nos blocos de cubagem ou de lavra, pois estes tam-

\section{REFERÊNCIAS BIBLIOGRÁFICAS}

BARNES, M.P. 1980. Computer assisted mineral appraisal and feasibility. New York, Soc. Min. Eng. 167p.

FINNEY, D.J. 1941. On the distribution of a variate whose logarithm is normally distributed. J. Royal Stat. Soc., Supp.7(2):155-161.

KIM, Y.C. 1988. GEOBASE program documentation. Tucson, 22p.

1990. Introductory geostatistics and mine planning. Tucson, $139 \mathrm{p}$.

KUYUMJIAN, R.M. 1990. As zonas de alteração associadas ao depósito de cobre-ouro de Chapada, Goiás, Brasil. In: Congr. Bras. Geol., 36, Natal, 1990. Anais...Natal, SBG, v.3, p.1172-1178.

RICHARDSON, S.V.; KESLER, S.E.; ESSENE, E.J. 1986. Origin and geochemistry of the Chapada Cu-Au Deposit, Goiás, Brasil: A metamorphosed wall-rock porphyry copper deposit. Econ. Geol., 81: 1884-1898. bém deverão apresentar formas de distribuição próximas das distribuições iniciais, pois, caso contrário, a suavização da distribuição dos teores nos blocos indicará que houve uma generalização muito grande de teores.

\section{AGRADECIMENTOS}

$\mathrm{O}$ autor expressa os seus sinceros agradecimentos aos Profs. Drs. Gilberto Amaral e Jorge Silva Bettencourt pela orientação dada na elaboração da sua Tese de Doutoramento, da qual se originou este artigo. Agradece igualmente à Eluma S.A. que - por meio de seu Diretor, Dr. Júlio C. Senna - permitiu a utilização dos dados da Jazida de Cobre de Chapada e a publicação deste artigo. Por fim, ao Instituto de Geociências da USP, que ofereceu os recursos necessários à elaboração da Tese.

SILVA, J.A. 1979. Relatório final de pesquisa. São Paulo, Mineração Serras do LesteMINERALESTE. 8 vols.

1981. Relatório complementar para atualização de aspectos técnicos. Mineração Serras do Leste-MINERALESTE. 9 vols.

\& SÁ, J.A.G. 1988. Jazida de Cobre de Chapada, Mara Rosa, Goiás. In: Schobbenhaus, C. \& Coelho, C.E.S. (coord. ger.) Principais depósitos minerais do Brasil. Brasília, DNPM. Vol. III, p. $55-60$.

YAMAMOTO, J.K. 1991. Comparação de métodos computacionais para avaliação de reservas: um estudo de caso na Jazida de Cobre de Chapada, GO. São Paulo, Instituto de Geociências-USP. 175p. 